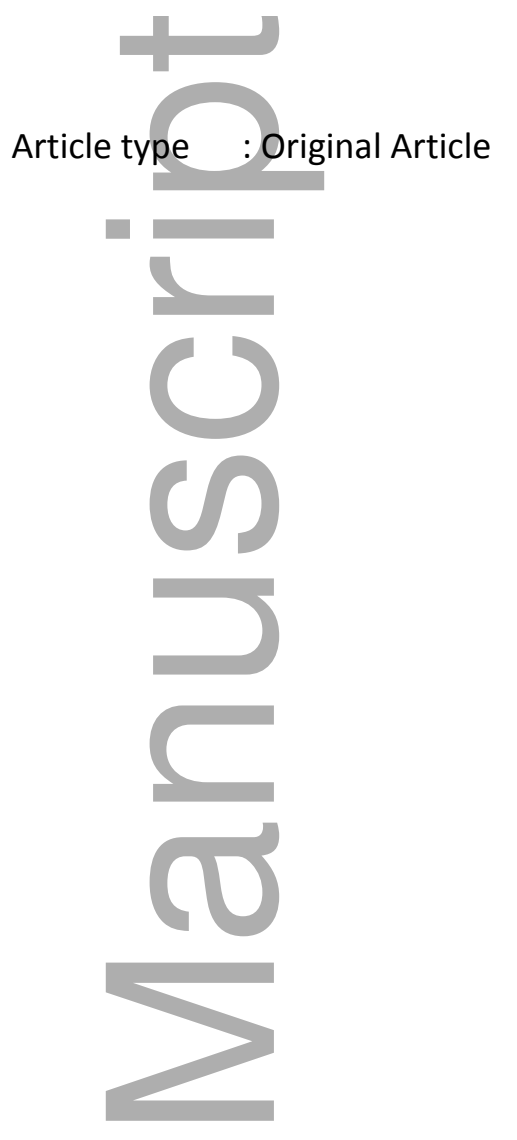

Word count: 4525

\title{
Predictors and consequences of health anxiety symptoms: A novel twin modeling study
}

Clara López-Solà ${ }^{1}$, Minh Bui ${ }^{2}$, John L Hopper ${ }^{2,3}$, Leonardo F Fontenelle ${ }^{4,5,6}$, Chris G Davey ${ }^{7,8,9}$, Christos Pantelis $^{9}$, Pino Alonso ${ }^{10,11}$, Odile van den Heuvel ${ }^{12}$, Ben J Harrison ${ }^{9 *}$.

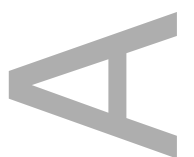

1 Adult Mental Health Department, Parc Taulí University Hospital, Universitat Autònoma de Barcelona, Sabadell, Spain. CIBERSAM (Centro de Investigación en Red de Salud Mental), Carlos III Health Institute.

This is the author manuscript accepted for publication and has undergone full peer review but has not been through the copyediting, typesetting, pagination and proofreading process, which may lead to differences between this version and the Version of Record. Please cite this article as doi: $10.1111 /$ acps.12850

This article is protected by copyright. All rights reserved 
2 Centre for Epidemiology and Biostatistics, Melbourne School of Population Health, The University of Melbourne, Melbourne, Australia

3Department of Family Medicine, Samsung Medical Center, Sungkyunkwan University School of Medicine, Irwon-ro 81, Gangnamgu, Seoul, South Korea

4 Programa de Transtornos Obsessivo-Compulsivos e de Ansiedade, Instituto de Psiquiatria, Universidade Federal do Rio de Janeiro (UFRJ), Rio de

Janeiro, Brazil

5 Instituto D’Or de Pesquisa e Ensino (IDOR), Rio de Janeiro, Brazil

6 Instituto de Saúde da Comunidade, Universidade Federal Fluminense (UFF), Rio de Janeiro, Brazil

7 Orygen, The National Centre of Excellence in Youth Mental Health, Melbourne, Australia

8 Centre for Youth Mental Health, The University of Melbourne, Melbourne, Australia

9 Department of Psychiatry, Melbourne Neuropsychiatry Centre, The University of Melbourne, Melbourne, Australia

10 Department of Psychiatry, Bellvitge University Hospital, Bellvitge Biomedical Research Institute (IDIBELL), Barcelona, Spain 11 Department of Clinical Sciences, School of Medicine, University of Barcelona, Barcelona, Spain. CIBERSAM (Centro de Investigación en Red de Salud Mental), Carlos III Health Institute.

12 Department of Anatomy and Neurosciences, VU university medical center (VUmc), Amsterdam, The Netherlands; Department of Psychiatry, VUmc, Amsterdam, The Netherlands; Neuroscience Campus Amsterdam, VU/VUmc, Amsterdam, The Netherlands; The OCD team, Haukeland University Hospital, Bergen, Norway.

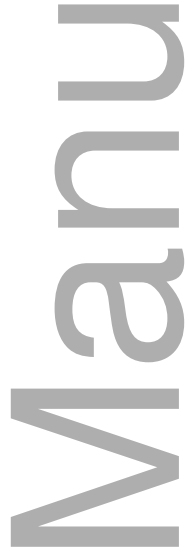

Address for correspondence:

B. J. Harrison, Melbourne Neuropsychiatry Centre | Department of Psychiatry

The University of Melbourne | Level 3, 161 Barry St. Carlton, VIC 3053

Phone: $\underline{(+613) 83441959 \text { | Email: habj@unimelb.edu.au }}$

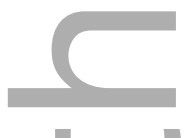

Abstract

Objective. The question of how to best conceptualize health anxiety (HA) from a diagnostic and etiological perspective remains debated. The aim was to examine the relationship between HA and the symptoms of anxiety and obsessive-compulsive related disorders in a normative twin population.

Method. 496 monozygotic adult twin pairs from the Australian Twin Registry participated in the study (age, 34.4 \pm 7.72 years; 59\% females). Validated scales were used to assess each domain. We applied a twin regression methodology -ICE 
FALCON- to determine if there was evidence consistent with 'causal' relationships between HA and other symptoms by fitting and comparing model estimates.

Results. Estimates were consistent with higher levels of obsessing ('unwanted thoughts') ( $\mathrm{p}=0.008)$, social anxiety $(\mathrm{p}=0.03)$ and body dysmorphic symptoms $(\mathrm{p}=0.008)$ causing higher levels of HA symptoms, and with higher levels of HA symptoms causing higher levels of physical/somatic anxiety symptoms $(\mathrm{p}=0.001)$. Conclusion. Obsessional thoughts, body dysmorphic concerns, and social anxiety symptoms may have a causal influence on HA. To report physical/somatic anxiety appears to be a consequence of the underlying presence of HA-related fears. Should our results be confirmed by longitudinal studies, the evaluation and treatment of HA may benefit from the consideration of these identified risk factors.

Keywords: health anxiety; obsessive-compulsive disorder, body dysmorphic disorder; anxiety, twin studies.

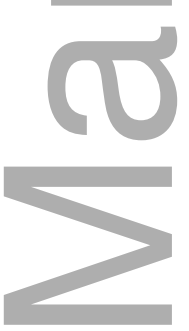

\section{Significant Outcomes.}

- Our noyel twin modeling results suggest that having higher levels of certain obsessive-compulsive related symptoms and social anxiety symptoms increase one's risk of experiencing health anxiety (HA). Separately, HA-related fears increase one's risk of experiencing acute physical anxiety symptoms.

- This study may inform the development of more comprehensive etiological models of HA. Its results challenge existing diagnostic classification schemes, which consider HA to be mostly independent of anxious psychopathology.

- While our results require confirmation in longitudinal studies, they suggest that targeting specific obsessional thoughts, body dysmorphic concerns, and interpersonal relationships, may have specific therapeutic benefits in the evaluation and treatment of health anxiety. 


\section{Limitations}

- While the analysis methodology and cross-sectional design appropriately permit tests of causation, the identified relationships should be confirmed by future studies, including longitudinal and twin designs.

- We have relied on a dimensional approach to assessing psychiatric symptom domains in a normative twin population. Despite being a valid and common approach to assessing psychiatric constructs using population-based studies, our results should be extended to clinical populations with confirmed diagnoses, instead of relying on self-reported symptoms.

- Our study did not incorporate measures of other somatoform and anxiety disorder symptoms, such as disease/illness phobia.

\section{Introduction}

Severe health anxiety (HA), also referred to as hypochondriasis, is characterized by persistent preoccupation or fear of having, or a conviction that one has, one or more serious, progressive or life-threatening illnesses based on a catastrophic misinterpretation of bodily signs or symptoms. The preoccupation is manifested either by repetitive and excessive health-related behaviors and/or maladaptive avoidance behaviors (such as avoiding medical appointments). It is also associated with significant functional impairment and distress, as well as notably high rates of health care utilization (1). Recent work suggests that excessive forms of HA - representing one extreme of a continuum of HA-related fears in the population $(1,9)$ - may affect up to $7.4 \%$ of individuals especially during middle adulthood years. Yet despite these estimates, the conceptualization of HA from both a diagnostic and etiological perspective remains debated (4-7).

In the latest DSM, HA is split into two diagnoses: illness anxiety disorder and somatic symptom disorder, and remains in the 'somatic symptom and related disorders' chapter, whereas in ICD-11 it is listed with obsessive-compulsive disorder (OCD), body dysmorphic disorder (BDD) and hoarding disorder (HD) in the 'obsessive-compulsive and related disorders' (OCRD) section (5,7). In the latter case, shared features such as obsessional (intrusive and unwanted) thoughts and repetitive checking behaviors have been cited in support of its etiological link with OCRDs $(4,6,8)$. However, HA also remains distinct from OCRDs in terms of the frequency of somatic symptoms. It has been highlighted that while distressing thoughts about disease is the key feature of 
severe HA, individuals with OCD most often present intrusive thoughts unrelated to health, such as thoughts about harming others (9). On the other hand, because HA involves marked anxiety and preoccupation with benign bodily symptoms, it has also been linked etiologically with panic disorder (PD) (7). To a less extent, HA has been linked to other anxiety disorders, such as generalized anxiety disorder (GAD), based on high levels of comorbidity (around 28\%) (11) and due to the co-occurrence of worries in both disorders (12); although see (13). Disease/illness phobia (a simple phobia), which refers to the fear of developing a serious illness (without the conviction that they already have such an illness), has been also associated with HA. However, people with illness phobia tend to have few or no somatic symptoms and relatively good insight, perceiving their fears as excessive or unreasonable (13). Finally, less studied, problems dealing with social relationships (14) and social fears of criticism have also been described in people with HA (15). Clearly, further research is needed to understand the etiological basis of HA and its relationship to these other frequently comorbid disorders.

\section{Aims of the Study}

Our aim was to employ a novel twin modeling approach - inference on causation from examination of familial confounding (ICE FALCON) - to test for evidence consistent with the existence of 'causal' relationships between HA symptoms and the symptoms of these other disorders (16-18).

In applying ICE FALCON, our hypotheses were that panic symptoms specifically, the fear of bodily anxiety symptoms -, body dysmorphic concern symptoms, chronic stress-tension symptoms and specific OCD symptom dimensions (washing, checking and obsessing/unwanted intrusive thoughts) would emerge as 'causal risk factors' for HA symptoms. Conversely, we hypothesized that other forms of anxiety symptoms, such as the reported presence of physical anxiety symptoms, as well as depressive symptoms, would increase as a consequence of HA. No causal relationships were expected between HA and social anxiety symptoms and OCD hoarding and symmetry/ordering symptoms. We reasoned that evidence of potential causal relationships between these symptom domains might provide insights into the etiological basis of HA and thus contribute to the ongoing debate about its diagnostic classification, and with potential relevance to its improved treatment. 


\section{Material and Methods}

\section{Participants}

Twins were recruited from the Australian Twin Registry (ATR), a national volunteer resource of twin pairs (19). All twins included in this study signed an online full consent information approved by the Human Research Ethics Committee and Mental Health Research from Melbourne (Australia) before answering any questionnaire. A total of 3,100 MZ twins were emailed by the ATR as part of a larger study (20). Twins were selected according to age (18 to 45 years) and known zygosity, and were balanced by gender (male-male and female-female). Twin pairs were randomly selected to receive the study email each week over a four-month period. Two weeks after receiving the initial invitation, non-responding twins were followed-up with a reminder email, followed by a further telephone reminder two weeks later. A second phone follow-up was performed for all remaining non-responders. Data collection ran for approximately one year between June 2011 and May 2012. A total of 1457 MZ twins (47\%) responded to the survey, 1643 (53\%) were non-responders. Of the responders, 383 were $\mathrm{MZ}$ singletons (excluded from this analysis), with an additional $41 \mathrm{MZ}$ pairs being removed due to unclear or missing zygosity. In total, our analyses incorporate data from $496 \mathrm{MZ}$ twin pairs ( $992 \mathrm{MZ}$ twins). All participants gave informed consent after receiving complete information on the study. The mean age of the twins was 34.4 years (S.D.= 7.72), and 59\% were female. See Table 1.

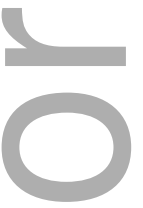

Table 1

\section{Instruments}

1) Health Anxiety Symptoms

The Whiteley Index (WI) is a 14-item questionnaire that assesses HA symptoms in a binary (Yes/No) format. All items are scored positively, except Item 9 "Is it easy for you to forget about yourself, and think about all sorts of other things?" which is negatively scored. Sum of each item derives in a total score. Factor analysis of WI reported only a one-factor solution in the general population (e.g. "Do you often worry about the possibility that you have got a serious illness?", "Do you get the feeling that people are not taking your illness seriously enough?”, "Do you think there is something 
seriously wrong with your body?"). The scale has shown satisfactory to good psychometric properties in three different samples (medical outpatients, general practice patients and general population) (21). Specifically, the WI demonstrates good discriminate validity between these three sample types. Internal consistency (Cronbach's alpha) was also high, ranging between 0.76 and 0.80 across the three samples

\section{2) Body Dysmorphic Concern Symptoms}

The Dysmorphic Concern Questionnaire (DCQ) is a 7-item questionnaire that assesses the degree of concern with physical appearance and body malfunctioning (e.g. "Have you ever been very concerned about some aspect of your physical appearance", "Have you ever spent a lot of time covering up defects in your appearance/bodily functioning"). Each item is rated on a 4-point Likert scale ( $0=$ not at all; $1=$ like most people; $2=$ more than other people; $3=$ much more than other people). Sum of each item derives in a total score ranging from 0 to 21 . It is a reliable and valid measure for the assessment of BDD symptoms (22).

\section{3) Obsessive-Compulsive Symptom Dimensions}

The Obsessive-Compulsive Inventory-Revised (OCI-R) is an 18-item questionnaire that assesses an individual's level of distress associated with OCD symptoms. Each item is rated on a 5-point Likert scale ranging from 0 (not at all) to 4 (extremely). Summing each item yields a total score ranging from 0 to 72 . The OCI-R total score has excellent psychometric properties (23). Acknowledging the heterogeneity of the disorder, the OCI-R evaluates 6 different OCD symptom dimensions: washing (sum of items 5, 11, 17), checking (sum of items 2, 8, 14), obsessing (sum of items $6,12,18$ ), hoarding (sum of items $1,7,13$ ), ordering (sum of items 3, 9, 15), and neutralizing (sum of items 4, 10, 16), some of them associated with different etiological patterns (24-26). Because of the utility of the OCI-R for examining OCD symptom dimensions, as demonstrated in our past work (26), we examined each of these dimensions in relation to HA symptoms.

\section{4) Depressive, Physical Anxiety and Stress Symptoms}

The Depression Anxiety Stress Scale (DASS) is a 21-item scale designed to assess three domains: Depression, Anxiety and Stress. Each item is rated on a 4-point Likert scale ranging from 0 (did not apply to me at all) to 3 (applied to me most of the time). The 
internal consistency and concurrent validity of the DASS-21 has been validated between acceptable to excellent ranges (27). The depression subscale is characterized principally by a loss of self-esteem and incentives, which assesses a state over the past week rather than a more stable trait (e.g., "I felt I wasn't worth much as a person"; "I couldn't seem to experience any positive feeling at all"). Summing items 3, 5, 10, 13, 16, 17 and 21 yields the 'depression' factor score. The anxiety subscale primarily emphasizes physical/somatic anxiety symptoms (e.g., dryness of the mouth, breathing difficulties, heart palpitations and general fear of panicking). Summing items 2, 4, 7, 9, 15, 19 and 20 yields the 'anxiety' factor score. The stress subscale focuses on persistent arousal, tension, irritability and tendency to overreact to stressful events (e.g., "I found it hard to wind down", "I tend to over-react to situations") (28). Summing items 1, 6, 8, $11,12,14$ and 18 yields the 'stress' factor score. All three subscales were included in the current analysis.

\section{5) Fear of Anxiety Symptoms}

The Anxiety Sensitivity Index (ASI) is a 16-item questionnaire that assesses fears related to the experience of anxiety symptoms (e.g., "It scares me when my heart beats rapidly", "Unusual body sensations scare me", "When I'm nervous, I worry that I might be mentally ill”). Each item is measured on a Likert scale ranging from 0 (no, just a little) to 4 (very much). Summing each item yields in a total score ranging from 0 to 64. It has adequate reliability and validity indices (29). ASI has been shown to distinguish between individuals with and without lifetime history of panic attacks, and between individuals experiencing panic attacks versus those with panic disorder (30). Further, patients with panic disorder were found to have higher ASI scores than all other anxiety disorders. A cut-off score of 30 has been demonstrated as indicator of panic disorder (31).

\section{6) Social Anxiety Symptoms}

The Social Phobia Inventory (SPIN) is a 17-item inventory that assesses different aspects related to social anxiety disorder (SAD) such as fear, avoidance and physiologic symptoms in different social situations (e.g., "parties and social events scare me", "Being criticized scares me a lot", "I avoid talking to people I don't know"). Each item is measured on a Likert scale ranging from 0 (not at all) to 4 (extremely). Sum of each 
item yields a total score ranging from 0 to 68 . It has shown excellent internal consistency and good test-retest reliability and convergent and discriminant validity. It distinguished well between those with social phobia and those with either PD or OCD (32).

\section{Statistical Analysis}

Summary statistics are presented as mean and standard deviation (SD) or percentage in Table 1. Missing values were imputed using the random forest method. Variables were transformed using a logarithm function $(a$ variable +1$)$ to reduce variability and then standardized to have mean zero and variance of one before conducting ICE FALCON analysis. To take into account correlation within the twin pairs, generalized estimating equation (GEE) method was used to conduct inference, with the mean function specified by each of the ICE FALCON model, which assumed to be linear and additive, and assumed exchangeable working correlation structure.

\section{Estimation of Cross-twin-Within-Trait Correlations}

Partial correlation, adjusted for age and gender, using Pearson method was initially used to explore correlation within twin pairs, between two traits (cross-trait) within individual and cross-twin cross-trait (i.e. correlation between twin 1 for a trait and twin 2 for another trait, and vice versa for twin 2 and twin 1). Within twin pairs correlation provides evidence for familial effects (genetic and shared environmental effects) on a trait, while within individual cross-trait correlations show the relationship exist for two traits, and finally the cross-twin cross-trait correlations provides an indication of the genetic and environmental factors that are share between two traits.

\section{Causal inference analysis}

We used the recently developed ICE FALCON (Inference on Causation from Examination of Familial Confounding) twin-regression methodology to make inference about the potential for there to be causal influences between factors (16,33-35). Briefly, ICE FALCON uses regression models to analyze twin pair data on both the outcome of interest and a familial predictor measured for both the twin and the cotwin. Comparisons of the changes in estimates from fitting different models allow inference to be made about putative causal relationships between the predictor and 
outcome variables. If the predictor is correlated within twin pairs and there is an association between the outcome of a given twin with the predictor of the co-twin that reduces after adjusting for the predictor of the given twin, then this is consistent with the existence of a causal relationship between the predictor and the outcome. If the associations between the outcome of a twin and the predictors of both the twin and the co-twin are the same, or similarly reduced, before and after adjusting for each other, there is no evidence for a causal relationship between the predictor and outcome.

ICE FALCON is similar to the Mendelian Randomisation approach to making inference on causation (36) which makes use of genetic risk scores as 'instrumental variables'. In ICE FALCON, the co-twin's exposure acts as a surrogate instrumental variable. The term 'causal' in this approach is used in the sense that if the predictor variable for a person was to be varied experimentally, then the value of the outcome variable of that person would be expected to change. In other words, the causal term used to refer to the idea of determining whether X symptoms appear before or after HA symptoms, but in any case refers to the causes underneath HA symptoms. In this sense, ICE FALCON twin methodology helps to understand that although different symptoms have been shown to be associated with HA, it is unknown whether they co-occur because they share underlying common factors (such as genetic and/or environmental factors) or because they appeared at different temporal times: one being a potential "predictor" of the other. Although familial confounders are an essential feature of the ICE FALCON approach, potential individual-specific moderators such as medication, previous treatment or psychiatric comorbidities do not impact the inferential process. This is because they cannot of themselves induce a cross-trait cross-pair association, even if there is a causal relationship between the predictor and the outcome.

ICE FALCON has been recently applied to study the potential causal associations between OCD and other compulsive and anxiety disorders symptoms, and between depression, anxiety and stress symptoms $(17,18)$. The underlying statistical model allows making inference about causation, not proving, playing a role between a predictor and an outcome via the 'elimination of familial confounding'. If the predictor is familial - that is, it is strongly correlated within twin pairs - and there is an association between the outcome variable of the index twin with the predictor of the cotwin that reduces after adjusting for the predictor of the index twin, then this is 
consistent with the existence of at least some causal relationship between the predictor and the outcome intra-subject. Note that this observation does not imply that the inferred causality is the only reason for a relationship between the predictor and the outcome. More details are given in the Supplementary Material.

For each pair of measures, we regressed one of them (the outcome) against the other (the predictor). We then reversed the direction of the regressions. For each scenario, we fitted three models: model I using the predictor of the index twin only; model II using the predictor of the co-twin only; and model III using the predictors of both the index twin and co-twin. Variables were log transformed (after adding 1 to make sure no variable has a zero value) and then standardized to have mean of 0 and a variance of 1. Generalized estimating equations (GEE), which take into account correlation in the outcome variable within twin pairs, were used to fit ordinary regression models, adjusting for sex and age.

To make statistical inference, the method relies on conducting one-tailed tests of significance; because the data are from pairs of individuals, we obtained confidence intervals and conducted tests of significance of these one-tailed tests using nonparametric bootstrap methods. This involved randomly sampling twin pairs with replacement to obtain the same sample size as the original dataset, and then fitting the models to this new data set to get a new set of estimated parameters. The process was repeated 1,000 times to estimate the sampling distribution of the parameter estimates, from which a standard error was estimated by computing the standard deviation. The $\mathrm{R}$ packages (http://www.R-project.org/) 'geepack' (37) and 'randomForest' (38) were used to conduct GEE analysis and imputed missing value, and the bootstrap inference was conducted using in-house R scripts. Following convention, tests were considered to be nominally significant at $\mathrm{p}<0.05$ although multiple tests. This is because for each variable $X$, we considered two tests to see if $X$ caused HA or HA caused X, so these two tests need to be considered together to see if they gave consistent evidence for causation.

\section{Results}

General familial associations 
Table 2 demonstrates that all measures were correlated with each other within, between and across twin pairs (all $p<0.05$ ), a pre-requisite for applying the ICE FALCON approach.

Table 2 ------

Inference on causality of relationships

Table 3 provides the results of the twin modeling approach applied to HA and OCD symptoms and provides evidence consistent with there being causal relationships of OCD symptom domains on HA. For OCD symptoms (OCI Total), the cross-trait crosspair coefficient reduced from 0.142 in Model II to 0.091 in Model III, and this change was significant $(\mathrm{p}=0.025)$, while the within individual coefficient remained relatively stable from Model I to Model III. For the OCD symptom dimensions, this pattern was evident for obsessional thoughts (Obsessing subscale) $(\mathrm{p}=0.008)$, and marginally so for Washing ( $\mathrm{p}=0.057$ ), but not for the other symptom dimensions. When the roles were reversed, this pattern was not evident for HA as a predictor of any OCD measure as an outcome

Table 4 provides the results for HA and other symptoms. Applying the same approach to the changes in regression coefficients, there was evidence consistent with HA having a causal influence on physical anxiety symptoms (DASS-Anxiety, $\mathrm{p}=$ 0.001), and marginal evidence consistent with HA having a causal influence on depressive symptoms (DASS-Depression, $\mathrm{p}=0.062$ ) and fear of anxiety symptoms (ASI, $\mathrm{p}=0.087$ ). There was also evidence consistent with body dysmorphic symptoms (DCQ, $p=0.008$ ) and social anxiety symptoms (SPIN, $p=0.029$ ) having a causal influence on HA.

$$
\text { In }
$$

In both Tables 3 and 4, when the cross-trait cross-pair coefficient reduced significantly from Model II to Model III, it was still significant in Model III. This is consistent with there being familial factors (i.e. factors shared by the twins within a pair) influencing both traits.

A supplementary regression analysis between fear of having anxiety symptoms (ASI) and physical anxiety symptoms (DASS-Anxiety) was also performed. As demonstrated at Table S1 from supplementary material, there was evidence consistent 
with fear of anxiety measured by ASI having a causal influence on physical anxiety symptoms measured by the DASS-Anxiety $(\mathrm{p}=0.025)$.

Fig. 1 shows a representation of the predicted causal relationships between the factors.

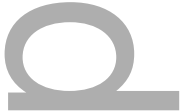

Tables $3 \& 4$, Figure 1

\section{Discussion}

Our study of monozygotic twin pairs confirms familial overlap between the symptoms of HA and two different diagnostic categories (anxiety and OCRDs). By exploiting this familial overlap, we have applied a twin regression modeling that is able to test for evidence consistent with there being distinct causal influences between some of these symptom domains. Our analyses suggest that HA symptoms are, in part, caused by having obsessional thoughts, body dysmorphic concerns and social anxiety, but not vice versa. Furthermore, having HA symptoms, in part, causes higher levels of physical anxiety symptoms, but not vice versa.

While further research, including longitudinal studies will be required to confirm these observed associations, they do suggest a potentially novel etiological model of HA that emphasizes certain cognitive (obsessional thoughts, also named as unwanted/forbidden thoughts), somatic (body dysmorphic) and social anxiety risk factors. At a cognitive level, we observed a distinct association between obsessional "unwanted" thoughts and HA symptoms. In OCD, this symptom dimension has been associated with maladaptive beliefs about the importance of one's thoughts: an underlying cognitive bias that often leads to high levels of thought-action fusion: that is, where thinking is appraised as the same as acting. Our findings raise the possibility that an "obsessional thinking style" measured with the obsessing subscale (e.g. having difficulties suppressing unpleasant thoughts, having difficulties of controlling their thoughts and overthinking excessively), including such cognitive biases (e.g. thoughtaction fusion), may have a greater causal influence on HA than is currently conceptualized. Although recent work has shown that HA is associated with "uncontrollability of worrying" and "danger of thinking" (39), these cognitive dimensions have only been marginally studied compared to the prominent cognitivebehavioral models of OCD. 
A causal association between body dysmorphic concerns and HA symptoms is generally consistent with the notion that heightened bodily awareness is a fundamental underlying characteristic of HA, as emphasized in the model of Wells (10). Specifically, our results suggest that a preoccupation with one's bodily appearance may have a causal influence that produces the manifestation of HA-related fears. There is some clinical evidence to suggest a specific overlap between BDD and HA (40). Conceptually, this result also appears to align with the classification of HA together with BDD/OCD in the OCRDs chapter of ICD-11. This classification reflects the idea that HA and BDD share two common characteristics: first, the presence of persistent and recurrent preoccupations, and second, the heightened vigilance towards - and catastrophic misinterpretation of -bodily anxiety symptoms (7).

Social anxiety symptoms measured with the SPIN also appear to causally predict HA symptoms on the basis of our modeling approach: a relationship that was not expected a priori. Nevertheless, it is of potential interest, especially considering Noyes and colleague's interpersonal model of HA (14). According to this model, HA is associated with an insecure attachment style that in adults gives rise to abnormal careseeking behavior and, consequentially, problems dealing with social relationships (14). Cognitive distortions related to social interaction could affect the safety signals from clinicians (41). Indeed, it has been reported that individuals with HA tend to present an increased prevalence of certain personality traits, such as mistrust or eccentric perceptions (42), with paranoid personality disorder being most frequently observed in HA ( $20 \%$ of cases) (43). An increased fear of social situations (as measure with the SPIN) suggests a bias in the interpretation of social cues, with a tendency to interpret them in excess and in a manner consistent with a "paranoid thinking style". Some other previous work suggests that social fears and low self-esteem may underlie HA-related cognitions (44), particularly social fears of criticism and intimacy (15), with a fear of intimacy being found to predict HA symptoms (41). Thus, although, cognitive models of HA (10) do not emphasize social anxiety fears as potential risk factors for HA, the above evidence suggests that these relationships may deserve further attention in future studies. 
Interestingly, as a 'predictor', HA was singularly associated with anxiety symptoms, which as measured by the DASS-Anxiety, focuses primarily on physical/somatic anxiety. This suggests that people with higher levels of HA symptoms are likely to-will experience more symptoms in this domain, which is an intuitive finding. A similar relationship is found in people with high levels of anxiety sensitivity (AS), a common characteristic of panic disorder (PD), whereby the specific fear of anxiety-related bodily sensations predicts higher levels of acute situational anxiety (45). However, there are important differences between the construct of HA and AS in regard to the appraisal/attribution of bodily anxiety symptoms. In HA, patients tend more to attribute such symptoms to a moderate or severe physical disease process and tend to be characterized by long periods of anxiety due to the delayed consequenees, whereas for people with high AS, particularly PD patients, somatic symptoms are more commonly attributed to cognitive/psychological factors (e.g. I will get crazy) and also related to immediate threats $(36,37)$. Nevertheless, in the current study, HA and AS (measured by the ASI) were found to be the most strongly correlated measures within individuals, and by contrast the lowest cross-twin correlation. To unpack this association further, we performed an extra regression analysis, which found evidence consistent with fear of anxiety symptoms (ASI) causally predicts physical anxiety symptoms measured by the DASS-Anxiety. Thus, despite other studies indicating that anxiety sensitivity does not predict HA symptoms when longitudinally assessed (48), we recognize that the overlap between these measures within participants may have precluded our ability to identify causal associations between them via the twin regression modeling.

In summary, $\mathrm{HA}$ is a complex psychiatric disorder that continues to challenge accurate etiological and diagnostic conceptualization. Our findings raises the possibility that treating social anxiety symptoms could have a therapeutic benefit in the reduction of the HA symptoms. Increasing the level of trust in others could help to improve the adherence to certain psychological and psychiatric treatments in HA patients. Regarding the "obsessional thinking style" it could be of interested to implement, as some recent studies are doing, mindfulness interventions $(49,50)$ to develop a friendly awareness towards thoughts, emotions and body sensations. This could help patients to disengage from over-thinking and developing a new and less reactive relationship with their inner experience (mind and body) without the urgency of getting rid of their distressing 
thoughts (e.g. obsessions). Finally, helping to reduce body dysmorphic concern symptoms could be of benefit in reducing the excessive attention focus to their somatic symptoms, so reducing the amplification of their body and leading to a less hyperchecking and anxiety. Clearly, further research - both longitudinal and clinical - is needed to advance current understanding of HA, particularly regarding its etiological basis, which ultimately promises to enhance its evidence-based treatment. The insights generated from our twin regression modeling approach are novel and identify specific relationships between HA and other frequently comorbid disorders that may prove compelling, if validated in subsequent studies, as major underlying risk factors.

\section{Acknowledgements}

The study was funded by an Early Career Researcher Grant to BJH from The University of Melbourne and was partially presented at the ECNP congress as a poster (51). BJH is supported by an NHMRC Career Development Fellowship (1124472). JLH is supported by a NHMRC Senior Principal Research Fellowship. CP is supported by a NHMRC Senior Principal Research Fellowship, and a Brain and Behavior Research Foundation (NARSAD) Distinguished Investigator Award. PA is supported by Instituto de Salud Carlos III (ISCIII) (PI14/00413], FEDER funds/European Regional Development Fund (ERDF) - a way to build Europe-). This research was facilitated through access to the Australian Twin Registry, a national resource supported by an Enabling Grant from the NHMRC.

\section{Declaration of Interest}

C.P. has participated on advisory boards for Janssen-Cilag and Lundbeck, and has received honoraria for talks presented at educational meetings organized by AstraZeneca, Janssen-Cilag and Lundbeck. None of the other authors has interests to declare.

Table 1. Summary statistics for socio-demographic and clinical characteristics.

\begin{tabular}{lcccc}
\hline Variable & $\mathrm{N}$ & Mean & $\mathrm{SD}$ & $\%$ Missing \\
\hline Continuous & & & & \\
\hline Age & 992 & 34.4 & 7.72 & 0 \\
\multicolumn{4}{c}{ Male-Male $=202$ pairs $(40.7 \%)$} \\
Sex & Female-Female $=294$ pairs $(59.3 \%)$ & \\
WI & 992 & 2.47 & 2.60 & 0
\end{tabular}




\begin{tabular}{|c|c|c|c|c|c|}
\hline \multicolumn{2}{|l|}{ DCQ } & 992 & 4.09 & 3.81 & 0 \\
\hline \multicolumn{2}{|l|}{ ASI } & 964 & 7.99 & 8.43 & 2.8 \\
\hline \multicolumn{2}{|l|}{ SPIN } & 969 & 11.09 & 11.71 & 2.3 \\
\hline \multirow[t]{4}{*}{ DASS } & Stress & 992 & 3.93 & 4.10 & 0 \\
\hline & Depression & 992 & 2.35 & 3.76 & 0 \\
\hline & Anxiety & 992 & 1.47 & 2.64 & 0 \\
\hline & Total & 992 & 7.75 & 9.23 & 0 \\
\hline \multirow[t]{6}{*}{$\mathrm{OCI}_{\square}$} & Total & 992 & 8.27 & 8.35 & 0 \\
\hline & Washing & 992 & 0.53 & 1.41 & 0 \\
\hline & Obsessing & 992 & 1.49 & 2.28 & 0 \\
\hline & Ordering & 992 & 2.23 & 2.32 & 0 \\
\hline & Checking & 992 & 1.41 & 1.86 & 0 \\
\hline & Hoarding & 992 & 1.88 & 2.01 & 0 \\
\hline \multicolumn{2}{|c|}{ Categorical } & $\mathrm{N}$ & $\%$ & & \\
\hline \multirow[t]{2}{*}{ Sex } & Female & 588 & 59.3 & & 0 \\
\hline & Male & 404 & 40.7 & & \\
\hline \multirow[t]{4}{*}{ Educatic } & Primary/Secondary School & 144 & 14.6 & & 0.5 \\
\hline & TAFE qualification & 272 & 27.6 & & \\
\hline & Undergraduate & 336 & 34.0 & & \\
\hline & Post-graduate & 235 & 23.8 & & \\
\hline \multirow[t]{5}{*}{ Marital } & Married/Partner & 596 & 60.6 & & 0.8 \\
\hline & Girlfriend/Boyfriend & 119 & 12.1 & & \\
\hline & Divorced/Separate & 42 & 4.30 & & \\
\hline & Single & 226 & 23.0 & & \\
\hline & Widowed & 1 & 0.10 & & \\
\hline \multirow[t]{6}{*}{ Employ } & Student & 57 & 5.80 & & 0.9 \\
\hline & Unemployed & 27 & 2.75 & & \\
\hline & Self-employed & 98 & 10.0 & & \\
\hline & Part-time employed & 196 & 19.9 & & \\
\hline & Full time employed & 540 & 54.9 & & \\
\hline & Other & 65 & 6.61 & & \\
\hline
\end{tabular}

Mean and standard deviation computed using raw score.

$\mathrm{WI}=$ health anxiety symptoms, DCQ = body dysmorphic concern symptoms, ASI $=$ fear of anxiety symptoms, SPIN = social anxiety symptoms, DASS $=$ depression, physical anxiety and stress symptoms, and $\mathrm{OCI}=$ obsessive-compulsive symptom dimensions. 
Table 2. Correlations within twin pairs, within-individuals but cross-trait, and cross-twin crosstrait, adjusted for age and sex, between health anxiety symptoms and each other anxiety, depression and obsessive-compulsive related disorder symptom dimension.

\begin{tabular}{lccc}
\hline & $\begin{array}{c}\text { Within twin pairs } \\
\text { correlation }\end{array}$ & $\begin{array}{c}\text { Within individual } \\
\text { cross-trait }\end{array}$ & $\begin{array}{c}\text { Cross-twin cross- } \\
\text { trait }\end{array}$ \\
& $\rho(95 \% \mathrm{CI})$ & $\rho(95 \% \mathrm{CI})$ & $\rho(95 \% \mathrm{CI})$ \\
\hline WI & $0.34(0.26,0.41)$ & $\mathrm{NA}$ & $\mathrm{NA}$ \\
DCQ & $0.40(0.32,0.47)$ & $0.41(0.36,0.46)$ & $0.23(0.17,0.28)$ \\
OCI-Total & $0.39(0.31,0.46)$ & $0.41(0.36,0.46)$ & $0.24(0.18,0.29)$ \\
OCI-Washing & $0.39(0.32,0.47)$ & $0.30(0.24,0.36)$ & $0.21(0.15,0.27)$ \\
OCI-Obsessing & $0.39(0.31,0.46)$ & $0.42(0.37,0.47)$ & $0.25(0.19,0.31)$ \\
OCI-Ordering & $0.33(0.25,0.41)$ & $0.26(0.20,0.31)$ & $0.15(0.09,0.21)$ \\
OCI-Checking & $0.37(0.29,0.44)$ & $0.37(0.31,0.42)$ & $0.18(0.12,0.24)$ \\
OCI-Hoarding & $0.30(0.22,0.38)$ & $0.23(0.17,0.29)$ & $0.12(0.06,0.18)$ \\
ASI & $0.30(0.22,0.38)$ & $0.48(0.43,0.53)$ & $0.19(0.13,0.25)$ \\
DPIN & $0.43(0.35,0.50)$ & $0.34(0.28,0.39)$ & $0.17(0.11,0.23)$ \\
DASS-Anxiety & $0.27(0.19,0.35)$ & $0.45(0.40,0.50)$ & $0.25(0.19,0.30)$ \\
DASS-Stress & $0.34(0.26,0.41)$ & $0.37(0.31,0.42)$ & $0.20(0.14,0.26)$ \\
\hline WIS-Depression & $0.31(0.24,0.35)$ & $0.36(0.31,0.41)$ & $0.19(0.13,0.25)$ \\
\hline
\end{tabular}

\footnotetext{
WI, Whiteley Index (health anxiety symptoms); DCQ, Dysmorphic Concern Questionnaire (body dysmorphic concern symptoms); OCI, Obsessive-Compulsive Inventory (obsessive-compulsive symptom dimensions); DASS, Depression Anxiety and Stress Scale (depression, physical anxiety and stress symptoms); ASI, Anxiety Sensitivity Index (fear of anxiety symptoms); SPIN, Social Phobia Inventory (social anxiety symptoms). $\rho=$ correlation coefficient.
} 


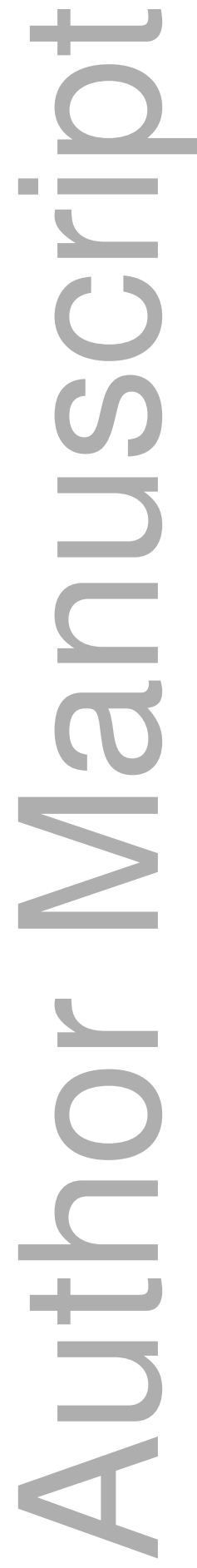

This article is protected by copyright. All rights reserved 
Table 3. ICE- FALCON model fits testing for evidence consistent with causation in both directions between Health Anxiety symptoms and OCD symptom dimensions. Standardized regression coefficient estimates (Coef), standard error (s.e), and $P$-value $(p)$

\begin{tabular}{|c|c|c|c|c|c|c|c|c|c|c|c|c|}
\hline \multirow[b]{2}{*}{ Predictor - Outcome } & & \multicolumn{3}{|c|}{ Model I } & \multicolumn{3}{|c|}{ Model II } & \multicolumn{3}{|c|}{ Model III } & \multicolumn{2}{|c|}{ Change } \\
\hline & & Coef & s.e & $p$ & Coef & s.e & $p$ & Coef & s.e & $p$ & Absolute & $p^{*}$ \\
\hline \multirow{2}{*}{ OCI Total $(\mathrm{X})-\mathrm{HA}(\mathrm{Y})$} & Self & 0.375 & $\mathbf{0 . 0 3 0}$ & $<0.001$ & & & & 0.364 & $\mathbf{0 . 0 3 1}$ & $<0.001$ & & \\
\hline & Cotwin & & & & 0.142 & $\mathbf{0 . 0 3 7}$ & $<0.001$ & 0.091 & 0.032 & 0.004 & -0.051 & 0.025 \\
\hline Washing $(\mathrm{X})-\mathrm{HA}(\mathrm{Y})$ & Self & 0.273 & 0.034 & $<0.001$ & & & & 0.259 & 0.034 & $<0.001$ & & \\
\hline $\operatorname{Obsessing}(X)-$ HA $(Y)$ & $\begin{array}{l}\text { Cotwin } \\
\text { Self }\end{array}$ & 0.397 & $\mathbf{0 . 0 3 0}$ & $<0.001$ & 0.145 & 0.037 & $<0.001$ & $\begin{array}{l}0.108 \\
\mathbf{0 . 3 8 0}\end{array}$ & $\begin{array}{l}0.030 \\
\mathbf{0 . 0 3 1}\end{array}$ & $\begin{array}{l}<0.001 \\
<\mathbf{0 . 0 0 0}\end{array}$ & -0.038 & 0.057 \\
\hline $\operatorname{Hoarding}(\mathrm{X})-\mathrm{HA}(\mathrm{Y})$ & $\begin{array}{l}\text { Cotwin } \\
\text { Self }\end{array}$ & 0.209 & 0.033 & $<0.001$ & 0.179 & 0.035 & $<0.001$ & $\begin{array}{l}\mathbf{0 . 1 0 5} \\
0.210\end{array}$ & $\begin{array}{l}\mathbf{0 . 0 3 1} \\
0.032\end{array}$ & $\begin{array}{c}\mathbf{0 . 0 0 1} \\
<0.001\end{array}$ & -0.074 & 0.008 \\
\hline $\operatorname{Ordering}(\mathrm{X})-\mathrm{HA}(\mathrm{Y})$ & $\begin{array}{l}\text { Cotwin } \\
\text { Self }\end{array}$ & 0.231 & 0.030 & $<0.001$ & 0.057 & 0.034 & 0.094 & $\begin{array}{l}0.060 \\
0.229\end{array}$ & $\begin{array}{l}0.032 \\
0.030\end{array}$ & $\begin{array}{c}0.061 \\
<0.001\end{array}$ & NS* & NS* \\
\hline \multirow{3}{*}{ Checking $(\mathrm{X})-\mathrm{HA}(\mathrm{Y})$} & Cotwin & & & & 0.080 & 0.033 & 0.015 & 0.073 & 0.030 & 0.017 & -0.007 & 0.328 \\
\hline & Self & 0.352 & 0.031 & $<0.001$ & & & & 0.347 & 0.031 & $<0.001$ & & \\
\hline & Cotwin & & & & 0.092 & 0.035 & 0.008 & 0.055 & 0.031 & 0.070 & -0.036 & 0.097 \\
\hline HA $(X)-$ OCI Total $(Y)$ & Self & 0.370 & 0.029 & $<0.001$ & & & & 0.365 & 0.029 & $<0.001$ & & \\
\hline $\mathrm{HA}(\mathrm{X})-\mathrm{Washing}(\mathrm{Y})$ & $\begin{array}{l}\text { Cotwin } \\
\text { Self }\end{array}$ & 0.262 & 0.040 & $<0.001$ & 0.123 & 0.037 & 0.001 & $\begin{array}{l}0.103 \\
0.262\end{array}$ & $\begin{array}{l}0.031 \\
0.039\end{array}$ & $\begin{array}{c}0.001 \\
<0.001\end{array}$ & -0.020 & 0.250 \\
\hline $\mathrm{HA}(\mathrm{X})-\mathrm{Ob} \operatorname{sessing}(\mathrm{Y})$ & $\begin{array}{l}\text { Cotwin } \\
\text { Self }\end{array}$ & 0.384 & 0.031 & $<0.001$ & 0.123 & 0.039 & 0.002 & $\begin{array}{l}0.124 \\
0.379\end{array}$ & $\begin{array}{l}0.036 \\
0.031\end{array}$ & $\begin{array}{l}<0.001 \\
<0.001\end{array}$ & 0.001 & 0.477 \\
\hline HA $(\mathrm{X})-$ Hoarding $(\mathrm{Y})$ & $\begin{array}{l}\text { Cotwin } \\
\text { Self }\end{array}$ & 0.218 & 0.033 & $<0.001$ & 0.146 & 0.036 & $<0.001$ & $\begin{array}{l}0.126 \\
0.215\end{array}$ & $\begin{array}{l}0.030 \\
0.034\end{array}$ & $\begin{array}{l}<0.001 \\
<0.001\end{array}$ & -0.020 & 0.274 \\
\hline $\mathrm{HA}(\mathrm{X})-$ Ordering $(\mathrm{Y})$ & $\begin{array}{l}\text { Cotwin } \\
\text { Self }\end{array}$ & 0.237 & 0.032 & $<0.001$ & 0.068 & 0.035 & 0.052 & $\begin{array}{l}0.053 \\
0.234\end{array}$ & $\begin{array}{l}0.033 \\
0.032\end{array}$ & $\begin{array}{l}0.106 \\
<0.001\end{array}$ & NS* & NS* \\
\hline HA $(X)=$ Checking $(Y)$ & $\begin{array}{l}\text { Cotwin } \\
\text { Self }\end{array}$ & 0.346 & 0.031 & $<0.001$ & 0.083 & 0.034 & 0.014 & $\begin{array}{l}0.073 \\
0.345\end{array}$ & $\begin{array}{l}0.032 \\
0.031\end{array}$ & $\begin{array}{c}0.023 \\
<0.001\end{array}$ & -0.010 & 0.262 \\
\hline & Cotwin & & & & 0.072 & 0.035 & 0.038 & 0.069 & 0.030 & 0.021 & -0.003 & 0.457 \\
\hline
\end{tabular}

Abbreviations: HA, Health anxiety symptoms; OCI, Obsessive-Compulsive Inventory (obsessive-compulsive symptom dimensions); X, independent variable; Y, outcome variable; * $p$, pvalue for 1-side; NS, not significant.

Significant associations are presented in bold face.

This article is protected by copyright. All rights reserved 
The analyses were adjusted for sex and age.

\begin{tabular}{|c|c|c|c|c|c|c|c|c|c|c|c|c|}
\hline \multirow[b]{2}{*}{ Predictor — Outcome } & & \multicolumn{3}{|c|}{ Model I } & \multicolumn{3}{|c|}{ Model II } & \multicolumn{3}{|c|}{ Model III } & \multicolumn{2}{|c|}{ Change } \\
\hline & & Coef & s.e & $p$ & Coef & $\begin{array}{l}\text { s.e } \\
\text { s. }\end{array}$ & $p$ & Coef & s.e & $p$ & Absolute & $p^{*}$ \\
\hline \multirow[t]{16}{*}{$\mathrm{HA}(\mathrm{X})-\mathrm{DCQ}(\mathrm{Y})$} & Self & 0.372 & 0.028 & $<0.001$ & & & & 0.371 & 0.027 & $<0.001$ & & \\
\hline & Cotwin & & & & n 1 ine & $n \cap 25$ & $n \cap \cap 2$ & $n 1 \mathrm{n}$ & $n$ M) & $<n n \cap 1$ & ก กחE & ก 121 \\
\hline & & & & & & & & & & & & \\
\hline & & & & & & & & & & & & \\
\hline & & & & & & & & & & & & \\
\hline & & & & & & & & & & & & \\
\hline & & & & & & & & & & & & \\
\hline & & & & & & & & & & & & \\
\hline & & & & & & & & & & & & \\
\hline & & & & & & & & & & & & \\
\hline & & & & & & & & & & & & \\
\hline & & & & & & & & & & & & \\
\hline & & & & & & & & & & & & \\
\hline & & & & & & & & & & & & \\
\hline & & & & & & & & & & & & \\
\hline & & & & & & & & & & & & \\
\hline
\end{tabular}

This article is protected by copyright. All rights reserved 


\begin{tabular}{|c|c|c|c|c|c|c|c|c|c|c|c|c|}
\hline HA (X) - DASS-Anxiety (Y) & Self & 0.431 & $\mathbf{0 . 0 3 1}$ & $<0.001$ & \multirow[b]{2}{*}{0.207} & \multirow[b]{2}{*}{0.035} & \multirow[b]{2}{*}{$<0.001$} & 0.410 & $\mathbf{0 . 0 3 2}$ & $<0.001$ & \multirow[b]{2}{*}{$-\mathbf{0 . 0 9 8}$} & \multirow[b]{2}{*}{0.001} \\
\hline HA $(\mathrm{X})$ - DASS-Stress (Y) & $\begin{array}{l}\text { Cotwin } \\
\text { Self }\end{array}$ & 0.341 & 0.029 & $<0.001$ & & & & $\begin{array}{l}\mathbf{0 . 1 0 9} \\
0.336\end{array}$ & $\begin{array}{l}\mathbf{0 . 0 3 1} \\
0.029\end{array}$ & $\begin{array}{l}<\mathbf{0 . 0 0 1} \\
<0.001\end{array}$ & & \\
\hline HA (X) - DASS-Depression (Y) & $\begin{array}{l}\text { Cotwin } \\
\text { Self }\end{array}$ & 0.327 & 0.029 & $<0.0001$ & $\cap 1 \cap 8$ & $\cap \cap 22$ & $\cap \cap \cap 1$ & $\begin{array}{l}\cap \cap 85 \\
0.320\end{array}$ & $\begin{array}{l}\cap \Omega 90 \\
0.029\end{array}$ & $\begin{array}{r}\cap \cap \cap 1 \\
<0.0001\end{array}$ & _ก ก) & $\cap 10 \cap$ \\
\hline $\mathrm{HA}(\mathrm{X})-\mathrm{ASI}(\mathrm{Y})$ & $\begin{array}{l}\text { Cotwin } \\
\text { Self }\end{array}$ & 0.470 & 0.026 & $<0.001$ & ก 109 & $0 \cap 34$ & 00013 & $\begin{array}{l}0,077 \\
0.467\end{array}$ & $\begin{array}{l}0 \Omega 30 \\
0.027\end{array}$ & $\begin{array}{l}0,0186 \\
<0.001\end{array}$ & $-\cap \cap 37$ & $0 \cap 6 ?$ \\
\hline HA $(X)$ - Social Phobia (Y) & $\begin{array}{l}\text { Cotwin } \\
\text { Self }\end{array}$ & 0.314 & 0.028 & $<0.001$ & ก กо2 & $\cap \cap 28$ & $\cap \cap 12$ & $\begin{array}{l}\cap \Omega 27 \\
0.319\end{array}$ & $\begin{array}{l}\cap \cap 2 n \\
0.028\end{array}$ & $\begin{aligned} \cap 970 \\
<0.001\end{aligned}$ & $-\cap \cap 57$ & $\cap \cap 87$ \\
\hline & Cotwin & & & & م.25 & مـ24م & 0206 & م6مـم & م020مـ & 027 & NS* & NS* \\
\hline $\mathbf{D C Q}(\mathrm{X})-\mathrm{HA}(\mathrm{Y})$ & Self & 0.400 & $\mathbf{0 . 0 3 0}$ & $<0.001$ & & & & 0.388 & 0.030 & $<0.001$ & & \\
\hline DASS-Anxiety $(\mathrm{X})$ - HA (Y) & $\begin{array}{l}\text { Cotwin } \\
\text { Self }\end{array}$ & 0.419 & 0.028 & $<0.001$ & O 118 & $0 \Omega 27$ & $<\mathbf{n} \mathbf{n} \mathbf{1}$ & $\begin{array}{l}\mathbf{n} \mathbf{~ n 7 0} \\
0.412\end{array}$ & $\begin{array}{l}\mathbf{n} \mathbf{n 2 7} \\
0.028\end{array}$ & $<0.001$ & п กко & n nก) \\
\hline DASS-Stress $(\mathrm{X})-\mathrm{H}$ & $\begin{array}{l}\text { Cotwin } \\
\text { Self }\end{array}$ & 0.344 & 0.029 & $<0.001$ & 0.164 & 0.034 & $<0.001$ & $\begin{array}{l}0.137 \\
0.338\end{array}$ & $\begin{array}{l}0.028 \\
0.029\end{array}$ & $\begin{array}{l}<0.001 \\
<0.001\end{array}$ & -0.027 & 0.240 \\
\hline DASS-Depression $(\mathrm{X})-\mathrm{HA}(\mathrm{Y})$ & $\begin{array}{l}\text { Cotwin } \\
\text { Self }\end{array}$ & 0.319 & 0.030 & $<0.0001$ & 0.112 & 0.033 & 0.001 & $\begin{array}{l}0.084 \\
0.319\end{array}$ & $\begin{array}{l}0.028 \\
0.029\end{array}$ & $\begin{array}{r}0.003 \\
<0.0001\end{array}$ & -0.028 & 0.162 \\
\hline $\operatorname{ASI}(\mathrm{X})-\mathrm{HA}(\mathrm{Y})$ & $\begin{array}{l}\text { Cotwin } \\
\text { Self }\end{array}$ & 0.464 & 0.027 & $<0.001$ & 0.089 & 0.033 & 0.0079 & $\begin{array}{l}0.085 \\
0.463\end{array}$ & $\begin{array}{l}0.030 \\
0.027\end{array}$ & $\begin{array}{l}0.0038 \\
<0.001\end{array}$ & -0.003 & 0.447 \\
\hline Social Phobia $(X)-$ HA (Y) & $\begin{array}{l}\text { Cotwin } \\
\text { Self }\end{array}$ & 0.334 & 0.031 & $<0.001$ & 0.064 & 0.037 & 0.089 & $\begin{array}{l}0.053 \\
\mathbf{0 . 3 3 1}\end{array}$ & $\begin{array}{l}0.029 \\
\mathbf{0 . 0 3 2}\end{array}$ & $\begin{array}{r}0.068 \\
<\mathbf{0 . 0 0 1}\end{array}$ & -0.011 & 0.401 \\
\hline & Cotwin & & & & 0.079 & 0.035 & 0.022 & 0.029 & 0.031 & 0.347 & -0.050 & 0.029 \\
\hline
\end{tabular}

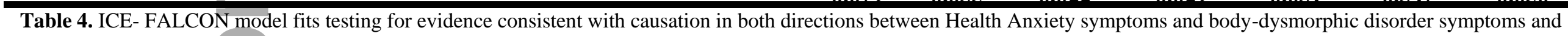
different anxiety symptoms. Standardized regression coefficient estimates (Coef), standard error (s.e), and $P$-value ( $p$ ) from regression models on monozygotic twin pairs.

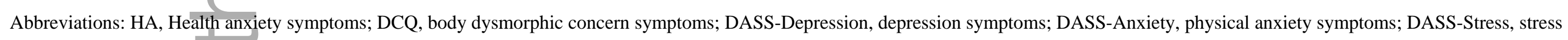
symptoms; ASI, fear of anxiety symptoms; $\mathrm{X}$, independent variable; $\mathrm{Y}$, outcome variable. NS; not significant; $p^{*}, p$-value for 1 -side.

Significant associations are presented in bold face.

The analyses were adjusted for sex and age.

This article is protected by copyright. All rights reserved 


\section{Figure legend}

Figure 1: Graphical representation of the causal relationships between the factors predicted form the ICE FALCON modelling. The assumed direction of the causal relationships is indicated by the directions of the arrows.

Social anxiety symptoms were measured by the SPIN scale, obsessional thoughts were measured by the obsessing subscale from the OCI-R, body dysmorphic concerns symptoms were measured by the DCQ scale and physical anxiety symptoms were measured by the DASS-Anxiety subscale.

\section{References}

1. Sunderland M, Newby JM, Andrews G. Health anxiety in Australia: Prevalence, comorbidity, disability and service use. Br J Psychiatry 2013;202:56-61.

2. FERGUSON E. A taxometric analysis of health anxiety. Psychol Med 2009;39:277-285.

3. Asmundson GJG, Abramowitz JS, Richter AA, Whedon M. Health Anxiety: Current Perspectives and Future Directions. Curr Psychiatry Rep 2010;12:306312.

4. BiENVENU OJ, SAMUELS JF, WUYeK L a et al. Is obsessive-compulsive disorder an anxiety disorder, and what, if any, are spectrum conditions? A family study perspective. Psychol Med 2012;42:1-13.

5. SteIn DJ, Kogan CS, AtMaCA M et al. The classification of ObsessiveCompulsive and Related Disorders in the ICD-11. J Affect Disord 2015;190:663674.

6. ABRAMOWITZ JS, BRADDOCK AE. Hypochondriasis: conceptualization, treatment, and relationship to obsessive-compulsive disorder. Psychiatr Clin North Am 2006;29:503-519.

7. VAN DEN Heuvel OA, VEale D, STEIN DJ. Hypochondriasis: considerations for ICD-11. Rev Bras Psiquiatr 2014;36 Suppl 1:21-27.

8. LOCHNER C, STEIN DJ. Does work on obsessive-compulsive spectrum disorders contribute to understanding the heterogeneity of obsessive-compulsive disorder? 
Prog Neuropsychopharmacol Biol Psychiatry 2006;30:353-361.

9. Torresan RC, RAmos-CERqueIra ATA, SHAVITT RG et al. Symptom dimensions, clinical course and comorbidity in men and women with obsessivecompulsive disorder. Psychiatry Res 2013;209:186-195.

10. WeLls A. Hypochondriasis: Health Anxiety. In: Cognitive Therapy of Anxiety Disorders. A practice manual and conceptual guide. John Wiley \& Sons., 1997, 133-166.

11. Scarella TM, Laferton JAC, Ahern DK, Fallon BA, Barsky A. The Relationship of Hypochondriasis to Anxiety, Depressive, and Somatoform Disorders. Psychosomatics 2016;57:200-207.

12. Lee S, IVy M Lam, Kathleen P Kwok, Candi M Leung. A community-based epidemiological study of health anxiety and generalized anxiety disorder. J

Anxiety Disord 2014;28:187-194.

13. STARCEYIC V. Hypochondriasis and health anxiety: conceptual challenges. Br J Psychiatry 2013;202:7-8.

14. NOYES R, StUART SP, LANGBEHn DR et al. Test of an interpersonal model of hypochondriasis. Psychosom Med 2003;65:292-300.

15. SCHWENZER M. Social fears in hypochondriasis. Psychol Rep 1996;78:971-975.

16. Bui M, Bjørnerem A, Ghasem-Zadeh A, Dite GS, Hopper JL, Seeman E. Architecture of cortical bone determines in part its remodelling and structural decay. Bone 2013;55:353-358.

17. DAVEY christopher G, LÓPEZ-SOLÀ C, BUI M et al. The effects of stress-tension on depression and anxiety symptoms: Evidence from a novel twin modeling analysis. Psychol Med 2016;in press.

18. LOPEZ-SOla C, FOnTENELle LF, Bui M et al. Aetiological overlap between obsessive-compulsive related and anxiety disorder symptoms: multivariate twin study. Br J Psychiatry 2016;208:26-33.

19. Hopper JL, Foley DL, White PA, Pollaers V. Australian Twin Registry: 30 years of progress. Twin Res Hum Genet 2013;16:34-42.

20. LÓPEZ-SolÀ C, FonTENELle LF, AlOnso P et al. Prevalence and Heritability of 
Obsessive-Compulsive Spectrum and Anxiety Disorder Symptoms: A Survey of the Australian Twin Registry. Am J Med Genet B Neuropsychiatr Genet 2014;165B:314-325.

21. Speckens AE, SPinhoven P, Sloekers PP, Bolk JH, van Hemert AM. A validation study of the Whitely Index, the Illness Attitude Scales, and the Somatosensory Amplification Scale in general medical and general practice patients. J Psychosom Res 1996;40:95-104.

22. OOSTHUIZEN P, LAMBert T, CASTLE DJ. Dysmorphic concern: prevalence and associations with clinical variables. Aust N Z J Psychiatry 1998;32:129-132.

23. FOA EB, HuPPERT JD, LEIBERG S et al. The Obsessive-Compulsive Inventory: development and validation of a short version. Psychol Assess 2002;14:485-496.

24. Rufer M, Fricke S, Moritz S, Kloss M, HAND I. Symptom dimensions in obsessive-compulsive disorder: prediction of cognitive-behavior therapy outcome. Acta Psychiatr Scand 2006;113:440-446.

25. LECKMAN JF, DENYS D, SIMPSON HB et al. Obsessive-compulsive disorder: a review of the diagnostic criteria and possible subtypes and dimensional specifiers for DSM-V. Depress Anxiety 2010;27:507-527.

26. LóPEZ-SolÀ C, Fontenelle LF, Verhulst B et al. Distinct Etiological Influences on Obsessive-Compulsive Symptom Dimensions: A Multivariate Twin Study. Depress Anxiety 2016;33:179-191.

27. Antony M, Bieling P, Cox B, Enns M, Swinson R. Psychometric properties of the 42-item and 21-item versions of the Depression Anxiety Stress Scales in clinical groups and a community sample. Psychol Assess 1998;10:176-181.

28. Osman A, Wong JL, Bagge CL, Freedenthal S, Gutierrez PM, Lozano G. The Depression Anxiety Stress Scales-21 (DASS-21): further examination of dimensions, scale reliability, and correlates. J Clin Psychol 2012;68:1322-1338.

29. REISS S, PETERSON RA, GURSKy DM, MCNALly RJ. Anxiety sensitivity, anxiety frequency and the prediction of fearfulness. Behav Res Ther 1986;24:1-8.

30. Rector NA, SzACUn-Shimizu K, LEybman M. Anxiety sensitivity within the anxiety disorders: disorder-specific sensitivities and depression comorbidity. 
Behav Res Ther 2007;45:1967-1975.

31. WeEms CF, HAYWARD C, KILLEN J, TAYLOR CB. A longitudinal investigation of anxiety sensitivity in adolescence. J Abnorm Psychol 2002;111:471-477.

32. Antony MM, Coons MJ, McCabe RE, Ashbaugh A, Swinson RP.

Psychometric properties of the social phobia inventory: further evaluation. Behav Res Ther 2006;44:1177-1185.

33. HOPPER JL, Bui QM, ERBAS B et al. Does eczema in infancy cause hay fever, asthma, or both in childhood? Insights from a novel regression model of sibling data. J Allergy Clin Immunol 2012;130:1117-1122.e1.

34. StOne J, Dite GS, Giles GG, Cawson J, English DR, Hopper JL. Inference about causation from examination of familial confounding: application to longitudinal twin data on mammographic density measures that predict breast cancer risk. Cancer Epidemiol Biomarkers Prev 2012;21:1149-1155.

35. Dite GS, GURRIN LC, BYRnES GB et al. Predictors of mammographic density: insights gained from a novel regression analysis of a twin study. Cancer Epidemiol Biomarkers Prev 2008;17:3474-3481.

36. PALMER TM, LAWLOR DA, HARBORD RM et al. Using multiple genetic variants as instrumental variables for modifiable risk factors. Stat Methods Med Res 2012;21:223-242.

37. HALEKOH U, HøJSGAARD S, YAN J. The R Package geepack for Generalized Estimating Equations Journal of Statistical Software. J Stat Softw 2006;15:1-11.

38. LIAW A, WIENER M. Classification and Regression by random Forest. R News J 2002;2:18-22.

39. BAILEY R, WELlS A. Metacognitive beliefs moderate the relationship between catastrophic misinterpretation and health anxiety. J Anxiety Disord 2015;34:814.

40. Conceição Costa DL, Chagas Assunção M, ArZeno Ferrão Y et al. Body dysmorphic disorder in patients with obsessive-compulsive disorder: prevalence and clinical correlates. Depress Anxiety 2012;29:966-975.

41. SCHWENZER M, MATHIAK K. Hypochondriacal attitudes comprise heterogeneous 
non-illness-related cognitions. BMC Psychiatry 2012;12:173.

42. NOYEs R, WATSON DB, LETUCHY EM et al. Relationship between hypochondriacal concerns and personality dimensions and traits in a military population. J Nerv Ment Dis 2005;193:110-118.

43. FALLON BA, HARPER KM, LANDA A et al. Personality Disorders in Hypochondriasis: Prevalence and Comparison with Two Anxiety Disorders. Psychosomatics 2012;53:566-574.

44. MARCUS DK, Association AP, SALKOVSKis P. et al. The cognitive-behavioral model of hypochondriasis. J Psychosom Res 1999;47:79-91.

45. Schmidt NB, KeOugh ME, Mitchell MA et al. Anxiety sensitivity: prospective prediction of anxiety among early adolescents. J Anxiety Disord 2010;24:503-508.

46. NENG JMB, WECK F. Attribution of Somatic Symptoms in Hypochondriasis. Clin Psychol Psychother 2015;22:116-124.

47. Salkovskis PM, Clark DM. Panic disorder and hypochondriasis. Adv Behav Res Ther 1993;15:23-48.

48. Olatunji BO, Wolitzky-Taylor KB, Elwood L, Connolly K, GonZales B, ARMSTRONG T. Anxiety sensitivity and health anxiety in a nonclinical sample: Specificity and prospective relations with clinical stress. Cognit Ther Res 2009;33:416-424.

49. Surawy C, McManus F, Muse K, Williams JMG. Mindfulness-Based Cognitive Therapy (MBCT) for Health Anxiety (Hypochondriasis): Rationale, Implementation and Case Illustration. Mindfulness (N Y) 2015;6:382-392.

50. McManus F, Surawy C, Muse K, VazQuez-Montes M, Williams JMG. A randomized clinical trial of mindfulness-based cognitive therapy versus unrestricted services for health anxiety (hypochondriasis). J Consult Clin Psychol 2012;80:817-828.

51. LOPEZ-SOLA C, BUi M, HOPPER JL et al. Understanding hypochondriasis: a novel twin study model of potential causal relationships with anxiety and OC-related disorder symptoms. Eur Neuropsychopharmacol 2017;26:S631 (poster). 


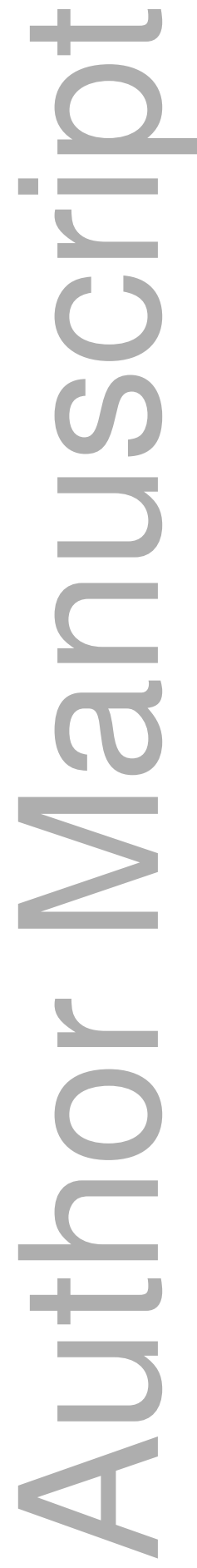

This article is protected by copyright. All rights reserved 


\section{PREDICTORS}

Increased risk to develop

HA symptoms

\section{CONSEQUENCES}

of HA symptoms

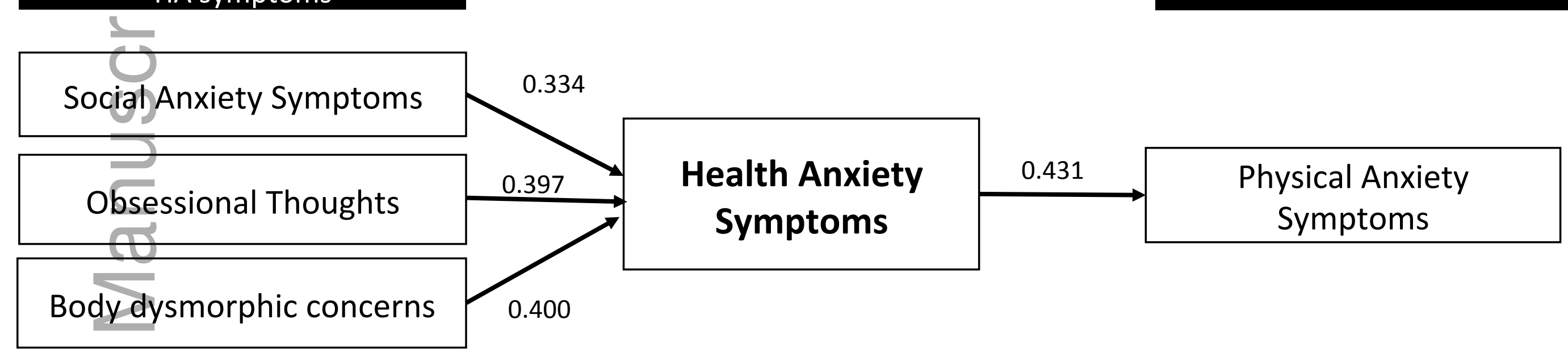

This article is protected by copyright. All rights reserved 


\section{University Library}

\section{- M M N E R VA A gateway to Melbourne's research publications}

Minerva Access is the Institutional Repository of The University of Melbourne

\section{Author/s:}

Lopez-Sola, C;Bui, M;Hopper, JL;Fontenelle, LF;Davey, CG;Pantelis, C;Alonso, P;van den Heuvel, OA;Harrison, BJ

Title:

Predictors and consequences of health anxiety symptoms: a novel twin modeling study

\section{Date:}

2018-03-01

\section{Citation:}

Lopez-Sola, C., Bui, M., Hopper, J. L., Fontenelle, L. F., Davey, C. G., Pantelis, C., Alonso, P., van den Heuvel, O. A. \& Harrison, B. J. (2018). Predictors and consequences of health anxiety symptoms: a novel twin modeling study. ACTA PSYCHIATRICA SCANDINAVICA, 137 (3), pp.241-251. https://doi.org/10.1111/acps.12850.

Persistent Link:

http://hdl.handle.net/11343/283511 